\title{
Sintering Unalloyed Titanium in DC Electrical Abnormal Glow Discharge
}

\author{
Allan Seeber ${ }^{\mathrm{a}}$,Aloisio Nelmo Klein ${ }^{\mathrm{b}}$, Carlos Viana Speller, Paola Egert', \\ Fabio Angheben Weber ${ }^{\mathrm{b}}$, Alexandre Lago ${ }^{\mathrm{b}}$ \\ ${ }^{a}$ Engenharia de Produção Mecânica - ACET/UNOESC, \\ Campus Joaçaba, Flor da Serra, 89600-000 Joaçaba - SC, Brazil \\ ${ }^{\mathrm{b}}$ Departamento de Engenharia Mecânica - LabMat/UFSC, \\ Campus Universitário, CP 476, Trindade, 88040-970 Florianópolis - SC, Brazil \\ 'Unidade Tecnológica-UNISUL, \\ Campus Grande Florianópolis, 88130-475 Palhoça - SC, Brazil
}

Received: November 5, 2009; Revised: February 14, 2010

\begin{abstract}
Powder metallurgy is widely used in the manufacture of components that have complex geometry. The good dimensional control, reduction in manufacturing steps and operating costs which has favored the use of this technique for manufacturing of titanium alloys components. However, the high affinity of this material with oxygen hinders strongly the sintering process. For this, the sintering associated with plasma technology can be considered an alternative technique for the processing of this material. The strict control of sintering atmosphere performed at low pressures and the reactive species present in the plasma environment can help to improve the sintering of this material. The results presented in this paper show a good correlation between the parameters used for the compaction of the samples and the microstructure develop during the plasma sintering of samples. The microstructure of the plasma assisted samples is also affected by the particular configuration used in the plasma reactor.
\end{abstract}

Keywords: plasma assisted sintering, dc abnormal glow discharge, powder metallurgy of titanium

\section{Introduction}

Since the 50s the Ti has been studied due its properties that favor its applicability in severe situations. This applicability can be related to its use in corrosive environments or in high mechanical requirements ${ }^{1}$. However, the difficulty in refining the metal and its high reactivity with oxygen leads to high production cost. As a consequence, the use of this material is limited to applications in which the steel can not be employed ${ }^{1-3}$. One example of application is for the manufacturing of prosthesis for medical and dental purposes. Yet, for this type of application, some mechanical properties must be modified to allow a better inter-connection between the bone tissue and the prosthetic component ${ }^{4}$. The reduction of the Young modulus is one example of this type of modification. Some authors ${ }^{5,6}$ believe that it's possible to decrease the value of the component's Young modulus by means of the introduction of some pores in the metal, which lessens the damage in the regions near the bone-implant interface. Thus, the powder metallurgy (PM) becomes an interesting manufacturing technique, since through it, it's possible to have a good dimensional control as well as a control on the porosity of the part.

On the other hand, Ti has high affinity for oxygen which constitutes a difficulty in processing this material from powder. The oxide layer that surrounds the Ti particles is formed rapidly and naturally, producing a passive barrier which hinders the formation of metallic contacts between the particles during the sintering. Thus, the Plasma Assisted Sintering presents itself as a technologically important alternative in the development of the Ti powder metallurgy. The high level of purity and the strict control of the chemical composition of the plasma environment, together with the presence of reactive and de- oxidizing chemical specimens in the glow discharge (plasma environment) favor the Sintering of $\mathrm{Ti}$ in the plasma assisted process. In this process, the efficiency is attributed to the heat transfer mechanisms and to the reactivity of the environment that surrounds the sample ${ }^{7}$. Studies carried out on sintering pure iron in abnormal luminescent discharge suggest that the plasma produced in argon and hydrogen environment acts reducing the oxides existing in the surface of the particles that constitute the sample $e^{8-12}$. In this technique, the sample is placed on one of the electrodes (cathode or anode). When connected on the cathode, the main source of heat will be the bombardment of the sample by ions and rapid neutral chemical specimens from the cathodic sheath. The strong electric field existing in this area strongly accelerates the ions towards the sample. The collision of these ions with air atoms and hydrogen molecules produces a flow of rapid neutral specimens that is directed to the sample, resulting in an energy transfer. The bombardment of the sample by the accelerated ions and by the rapid neutral specimens produces heat and pulverization of the material. In these conditions, the pulverized material redeposits itself over the samples, closing the superficial porosity.

When connected on the anode, the heating up of the sample is caused by the irradiation of heat generated in the cathode described above. In this case, the thermal efficiency of the process is inferior. Besides, the pulverization of material from the sample is not significant and the superficial porosity remains open.

The present article presents the results of a study on plasma assisted sintering of Titanium samples produced by die compaction of commercially pure Ti powder, sintered in two distinct configura- 
tions in a plasma reactor: a) the sample (green body) connected to the anode and b) the sample connected to the cathode. Some defects related to the rearrangement of the particles caused by wrong filling of the compaction die are also discussed in this paper.

\section{Experiments and Materials}

Table 1 presents the chemical composition of the Ti powder used in the experiments. The particle size was determined by laser granulometry. As it can be observed in Figure 1, the powder presents spherical-shaped particles. The samples were pressed in a double action die engaged to a universal testing machine with a capacity of $300 \mathrm{kN}$. Aiming to evaluate effects of rearrangement of the particles during the powder filling process on the resulting microstructure, a set of samples were prepared by filling the die with concomitant vibration and another set without vibration during the powder filling process. The pressure and loading speed used in both sets were the same. The cavity for the accommodation of the powder in the die was adjusted in order to assure that the pressed samples presented a maximum height of $0.0090 \mathrm{~m}$. To improve ejection step of the samples as well as to reduce density gradients, the die walls were lubricated with a Licowax and acetone solution.

The green densities of the samples were measured using the Archimedes method and were calculated with a level of reliability of $95 \%$. The preparation of the samples for metallographic analysis was initiated by a longitudinal cut with a diamond disc, following a vacuum impregnation with epoxy resin. Thus, it was possible to

Table 1. Specifications of the titanium powder commercially pure grade 1 , according to the manufacturer and apparent density values measured experimentally.

\begin{tabular}{|c|c|c|c|c|c|c|c|c|}
\hline \multicolumn{9}{|c|}{ Composition (\% weight) } \\
\hline $\mathrm{Ti}$ & $\mathrm{Fe}$ & $\mathrm{Al}$ & $\mathrm{Ni}$ & $\mathrm{C}$ & $\mathrm{H}$ & Mo & $\mathrm{O}$ & $\mathrm{N}$ \\
\hline$>99$ & $<0,2$ & $<0,015$ & $<0,9$ & $<0,1$ & $<0,3$ & $<0,4$ & $<0,18$ & $<0,03$ \\
\hline \multicolumn{4}{|c|}{ Description } & \multicolumn{5}{|c|}{ Titanium grade 1 (\# 41545) } \\
\hline \multicolumn{4}{|c|}{ Supplier } & \multicolumn{5}{|c|}{ Alfa Aesar } \\
\hline \multirow{3}{*}{\multicolumn{4}{|c|}{ Size }} & \multicolumn{5}{|c|}{$<89,95 \mu \mathrm{m}(90 \%)$} \\
\hline & & & & \multicolumn{5}{|c|}{$<64,32 \mu \mathrm{m}(50 \%)$} \\
\hline & & & & \multicolumn{5}{|c|}{$<46,94 \mu \mathrm{m}(10 \%)$} \\
\hline \multicolumn{4}{|c|}{ Purity } & \multicolumn{5}{|c|}{$>99 \%$ weight } \\
\hline \multicolumn{4}{|c|}{ Apparent Density } & \multicolumn{5}{|c|}{$2330 \mathrm{~kg} \cdot \mathrm{m}^{-3}$} \\
\hline \multicolumn{4}{|c|}{ Theoretical Density } & \multicolumn{5}{|c|}{$4510 \mathrm{~kg} \cdot \mathrm{m}^{-3}$} \\
\hline
\end{tabular}

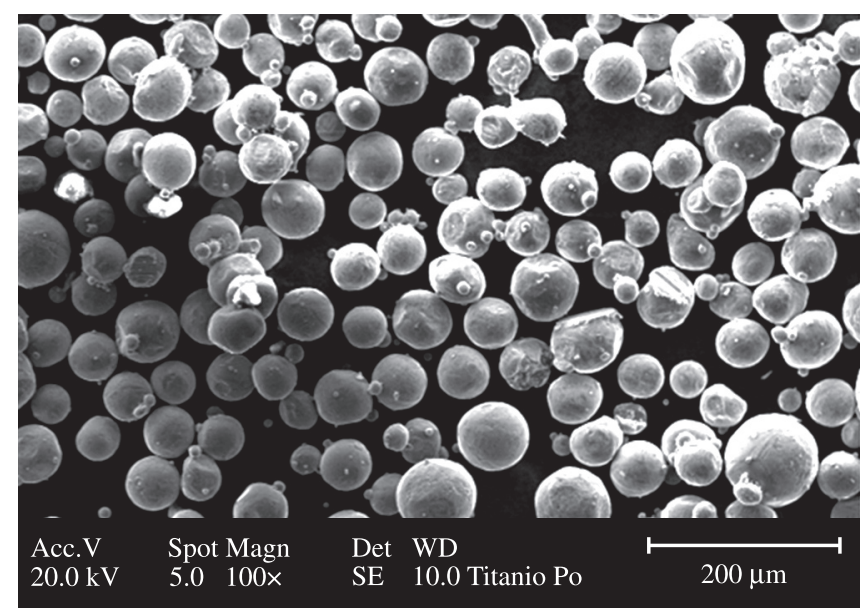

Figure 1. Size and shape of the titanium powder. reduce deformation on the edges of the pores during the grinding of the samples. The grinding and polishing of the samples were performed by an automatic polishing machine, following the procedures established by the manufacturer.

To achieve the desired sintering cycles in the plasma reactor, two distinct configurations for setting the samples were adopted: the sintering cycles with the sample connected to the cathode (CAC) and the sintering cycles with the sample connected to the anode (CAN). Both were performed in the experimental system shown in Figure 2.

This system consists of a sintering chamber (reactor) (1), made of stainless steel AISI 304 with $0.30 \mathrm{~m}$ in diameter and $0.30 \mathrm{~m}$ in height, a source of pulsed voltage (2) with adjustment of pulse time turned on, voltage taps of 400,500, 600 and $700 \mathrm{~V}$ with power of $3.5 \mathrm{~kW}$ in this last condition. The pumping out of the sintering chamber is done by a double stage vacuum pump (3). The atmosphere of the reactor consists of a mixture of Argon (99.999\%) + Hydrogen (99.998\%), in proportion $75-25 \%$, respectively. The gas flow to the inside of the reactor is controlled by two flow meters in a flow rate of $200 \mathrm{sccm}$ $\left(3.33 \times 10^{-6} \mathrm{~m}^{3} / \mathrm{s}\right)$.

The internal pressure of the reactor is monitored by a capacitive pressure sensor (5). The pressure is controlled by a diaphragm valve (6) positioned at the bottom of the reactor. The temperature is measured by a thermocouple (7) positioned below the sample.

The sintering of the samples on the CAC configuration (Figure 3) is performed by placing the sample on a Ti central electrode. In this condition, a negative potential of $700 \mathrm{~V}$ is applied to the sample.

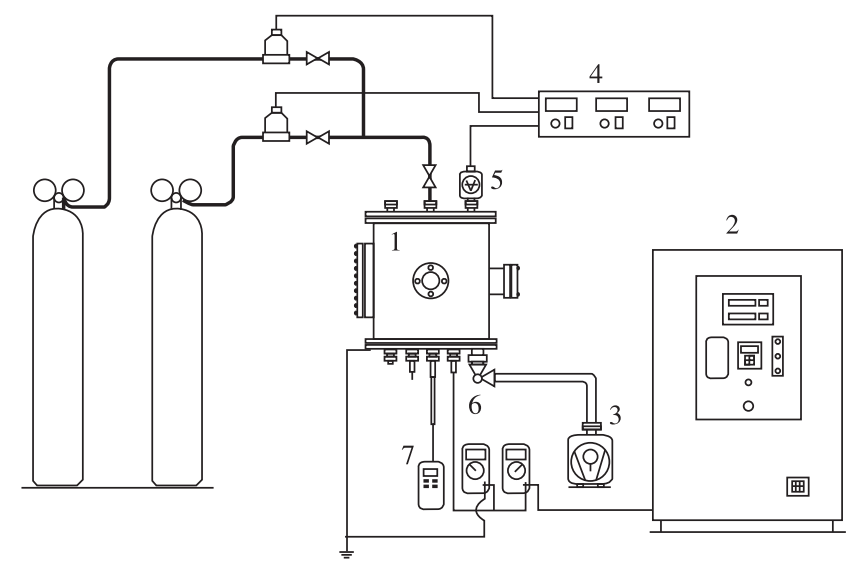

Figure 2. Schematic representation of the experimental system used in both sintering cycles: samples on the cathode and samples on the anode.

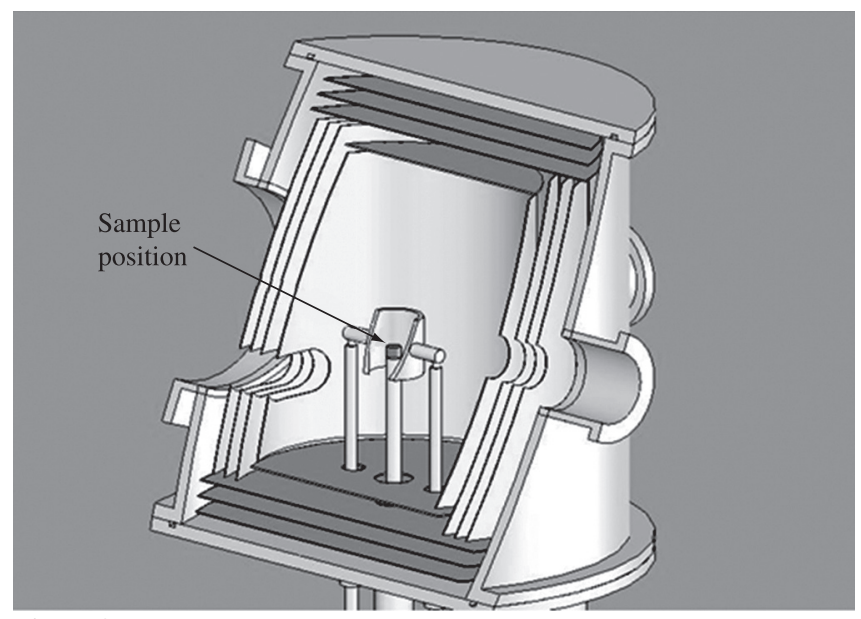

Figure 3. Schematic representation of the geometry of the reactor configuration CAC indicating the position of the sample. 
Surrounding the sample, a cylindrical electrode is polarized to the potential $0 \mathrm{~V}$ (ground) and is denominated anode.

The sample heating was done at a rate of $4.83 \mathrm{~K} / \mathrm{s}$ and in two steps. In the first step, a discharge in $\mathrm{H}_{2}$ atmosphere was used for heating up the sample up to $573 \mathrm{~K}$ and keeping the sample at this temperature for 900 seconds. This discharge step was applied for cleaning the surface of the sample. In the second step, argon was introduced into the reactor until the gas mixture reached a composition of $75 \% \mathrm{Ar}+25 \% \mathrm{H}_{2}$. The temperature of the sample was measured with a thermocouple positioned inside the central electrode. In this configuration, the samples were sintered in three different conditions (Table 2). These conditions were repeated for pressures of 400 and $1333 \mathrm{~Pa}$. In each case, the sample temperature was controlled by adjusting the time in which the pulse is on $\left(\mathrm{t}_{\mathrm{on}}\right)$ of the applied voltage.

In CAN configuration, the sample was placed on a flat electrode of titanium $0.080 \mathrm{~mm}$ long, horizontally arranged and connected to the reference potential (ground), as shown in Figure 4a. The heating of the sample was done by following the same steps as for setting CAC. However, in sintering cycles with the sample on the anode, only the condition 1 was adopted, repeating the tests for the pressures of 400 and $1333 \mathrm{~Pa}$. A negative potential of $700 \mathrm{~V}$ was applied to the outer electrode. The measurement of the sample temperature was made by connecting the thermocouple to a reference sample placed beside the sample to be sintered (Figure 4b). Considering that both are subjected to the same heating conditions, the temperature difference between them may be considered irrelevant.

Table 2. Description of the sintering cycle configuration sample on the cathode (CAC).

\begin{tabular}{lcc}
\hline & Time (seconds) & Temperature $(\mathrm{K})$ \\
\hline Condition 1 & 3600 & 1423 \\
Condition 2 & 3600 & 1473 \\
Condition 3 & 3600 & 1523 \\
\hline
\end{tabular}

\section{Results and Discussion}

\subsection{Plasma analysis}

The primary cleaning cycle of organic residues and the reduction of less stable oxides were carried out by a discharge of $\mathrm{H}_{2}$. Figure 5 shows the evolution of temperature in CAC and CAN settings to the pressures of 400 and $1333 \mathrm{~Pa}$ from the introduction of argon in the gas mixture.

As it can be seen, the two settings allow the system to achieve the desired sintering temperature. For the pressure of $400 \mathrm{~Pa}$, the pulse time turned on reaches extremely high values, reaching the limit of source control $(240 \mu \mathrm{s})$. This time corresponds to the time in which the discharge remains on, during the application of each pulse. The change of this parameter for a given applied voltage, produces variations in the total energy transferred to the cathode. The energy of the ions reaching the cathode is associated with the ratio of the voltage applied to the cathode and the product of the pressure (p) and the sheath thickness $(d)^{7}$. When the gas pressure increases, the cathode sheath thickness decreases and vice versa. Thus, the increasing of the pressure from $400 \mathrm{~Pa}$ to $1333 \mathrm{~Pa}$ suggests a decrease in sheath thickness in the order of three times.

As the applied voltage and the relationship "p.d" remains constant, one can expect that the energy of ions will be constant as well. However, the increase in pressure increases the amount of rapid species that are projected onto the surface of the cathode. Thus, the heating efficiency is increased when the sample is on the cathode, being necessary, a shorter pulse by the use of this configuration. This statement is associated with the consideration that for the same time pulse (eg $31 \mu \mathrm{s}$ ) the increase in pressure causes an increase in current density of more than $1180 \%$, from 29.4 to $347.9 \mathrm{Am}^{-2}$ (dotted line in Figure 6a). This analysis is also valid for the CAN configuration, but with less intensity.

In his work, Campo ${ }^{13}$ suggests that, depending on the collisions, the temperature at the surface is higher than in the core of the sample

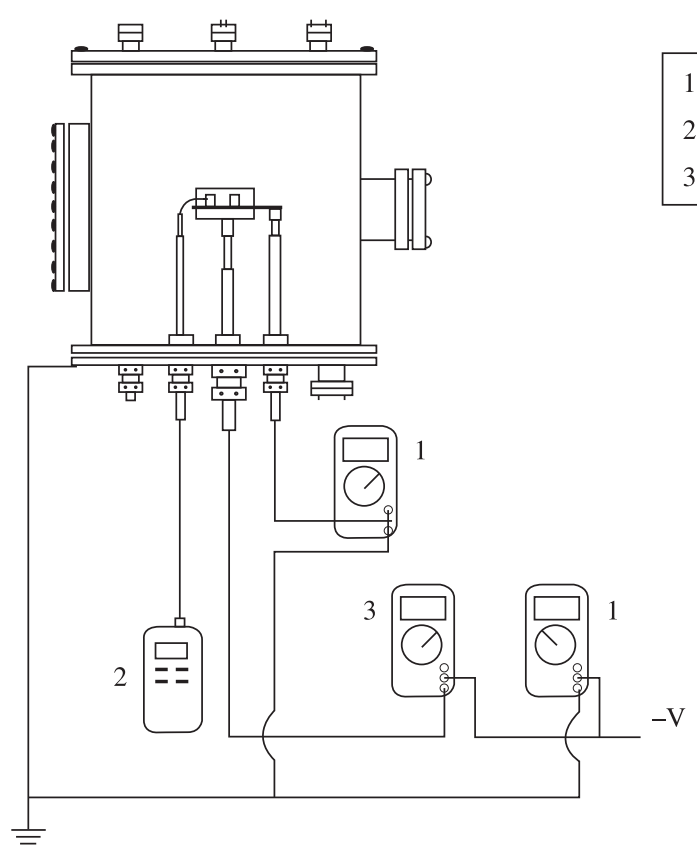

(a)

\section{Voltmeter \\ 2. Thermocouple \\ 3. Ammeter}

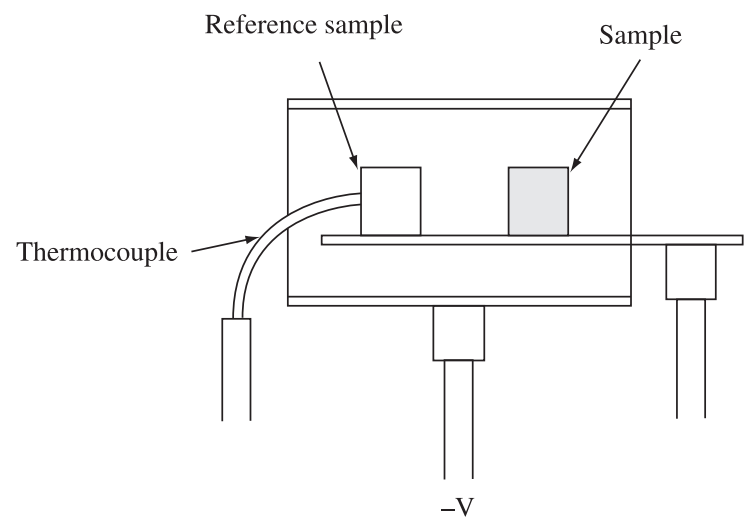

(b)

Figure 4. (a) Schematic representation of the configuration CAN and (b) detail of the position of the sintered sample and the reference sample. 


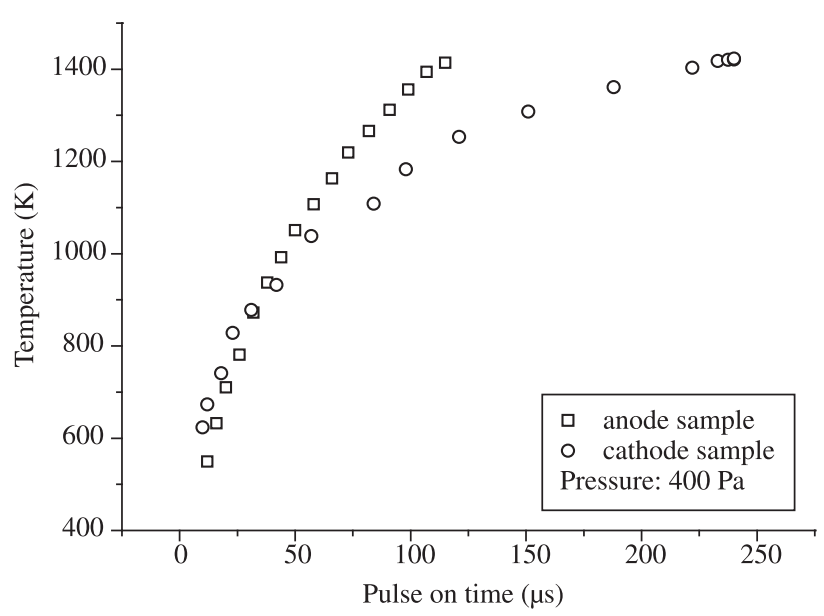

(a)

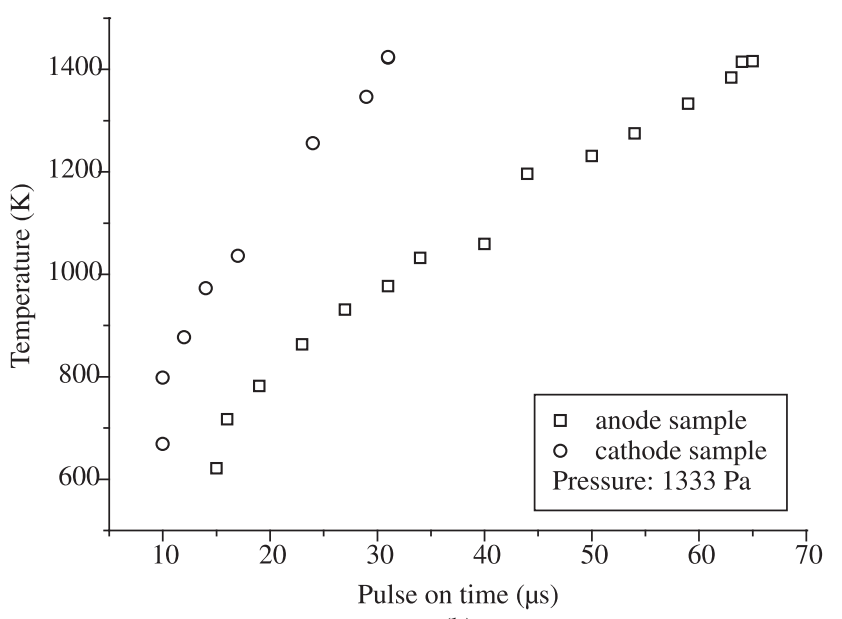

(b)

Figure 5. Evolution of temperature during heating of the sample for the settings "sample on the anode" and "sample on the cathode" for discharge with (a) $400 \mathrm{~Pa}$ and (b) $1333 \mathrm{~Pa}$.

Table 3. Comparison of changes in mass of samples sintered at a pressure of $1333 \mathrm{~Pa}$ in CAN setting.

\begin{tabular}{ccccc}
\hline \multicolumn{5}{c}{ CAN conditions } \\
\hline $\begin{array}{c}\text { Sintering } \\
\text { temperature } \\
(\mathrm{K})\end{array}$ & $\begin{array}{c}\mathrm{T}_{\text {on }} \\
(\mu \mathrm{s})\end{array}$ & $\begin{array}{c}\text { Initial } \\
\text { mass } \\
\left(\times 10^{-3} \mathrm{~kg}\right)\end{array}$ & $\begin{array}{c}\text { Final } \\
\text { mass } \\
\left(\times 10^{-3} \mathrm{~kg}\right)\end{array}$ & $\begin{array}{c}\text { Change } \\
\text { mass } \\
\left(\times 10^{-3} \mathrm{~kg}\right)\end{array}$ \\
\hline 1423 & 34 & 2,33 & 2,34 & 0,01 \\
1473 & 39 & 2,26 & 2,26 & 0,00 \\
1523 & 44 & 2,71 & 2,70 & $-0,01$ \\
\hline
\end{tabular}

favoring the transport mechanisms in this region and the mass loss due to the sputtering of the sample. However, the CAN samples configuration studied in the $1333 \mathrm{~Pa}$, showed a mass change in the order of $10 \mathrm{mg}$ compared to the original mass, as can be seen in Table 3 . This weight change was considered irrelevant, because it represents less than $0.5 \%$ of its initial value. A weight loss greater than measured was expected due to the sublimation of atoms as a function of vapour pressure and by evaporation of the lubricant adhered to the sample surface during its pressing. However, the measured mass variation represents the final result of both, mass loss and mass gain phenomena. It is possible that the mass variation observed was less than expected as a result of contamination of titanium atoms from the atmosphere of the reactor, mainly oxygen atoms and nitrogen considering the high stability of oxides and titanium-based nitrides.

\subsection{Analysis of the sintered samples}

Figures $7 \mathrm{a}$ and $7 \mathrm{~b}$ show micrographs obtained from the section of the samples pressed at 300 and $600 \mathrm{MPa}$ of compaction pressure, without vibration during die filling step, and sintered in plasma at a temperature of $1423 \mathrm{~K}$ in a cycle of 3600 seconds in the CAN and CAC setup, respectively. In Figure 7a, can be observed a denser region in the center of the image, with particles almost isolated in their surroundings. You can also observe the existence of long pores involving multiple particles. This type of density gradient is due to failure in filling the cavity of the compaction die with the powder which during the sintering step is accentuated by the collective mass transportation mechanism called "spin of particles". This effect is discussed in the literature ${ }^{14,15}$ and is due to diffusion of atoms and the resulting effect of rotation of particles during sintering. This phenomenon generates shrinkage in the volume of the material on

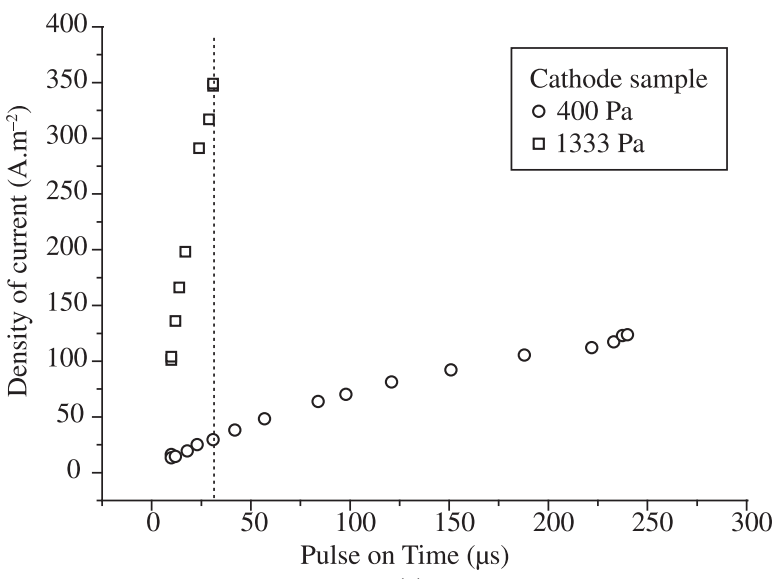

(a)

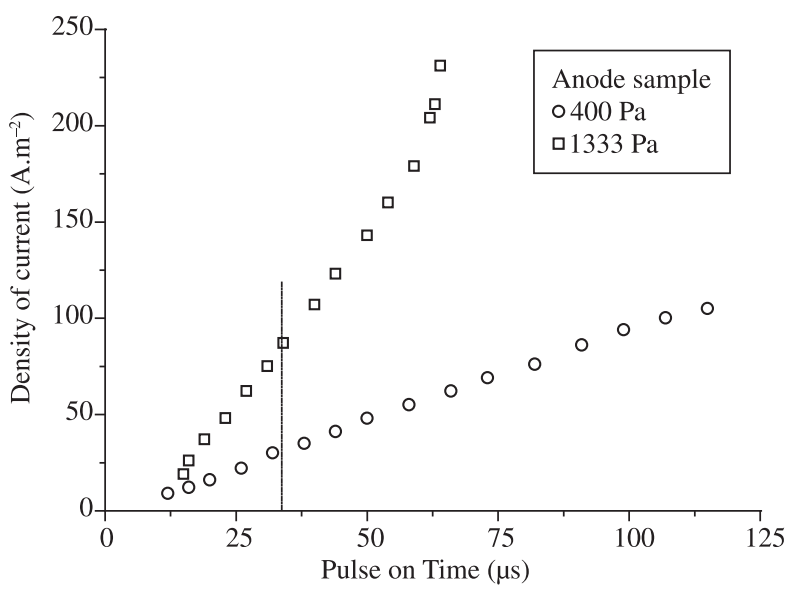

(b)

Figure 6. Behavior of the current density for the (a) CAC configuration and (b) CAN configuration.

both sides of the fault, increasing its size. The explanation is associated with the production of tensile stresses that are concentrated in the peripheral pores, resulting in greater continuity of matter in this region and the consequent increase in pore size. Accordingly, the 
rate of sintering decreases and there is an increase in the amount of interconnecting pores.

Figure $7 \mathrm{~b}$ shows the distribution of porosity from sintering of samples compacted with a load of $600 \mathrm{MPa}$, even without vibration of the compaction die. The presence of large and uneven pores, as well predominantly closed pores, can be observed. The difference between the porosity distribution of the sample pressed at $300 \mathrm{MPa}$ and that pressed at $600 \mathrm{MPa}$ is based on the fact that the high compaction pressure reduces the porosity gradients resulting from an inadequate powder filling of the compaction die cavity. Higher pressure leads to the formation, in a greater extent, of metal-metal contacts during the pressing step as a result of plastic flow to a greater extent. These considerations become more evident when we look to the results obtained with samples that were produced by filling the compaction die under vibration and pressing at $600 \mathrm{MPa}$, as shown in Figure 8.

Vibration promotes better rearrangement of particles during the filling of the die cavity, reducing the density gradients after filling. Thus, it can be noted that in the samples produced using vibration during the filling step of the die cavity, there are no fault lines in the microstructure of samples after sintering. As it can be seen in Figure 9, for the sample sintered on the cathode, the porosity observed is not open. The bombardment of the sample surface by ions and fast neutral species from the plasma causes the sputtering of the atoms from the surface of the sample that are thermalized and redeposit.

As described in Table 2, the sintering cycles were performed under a pressure of $1333 \mathrm{~Pa}$, for 3600 seconds and at temperatures of 1423 ,
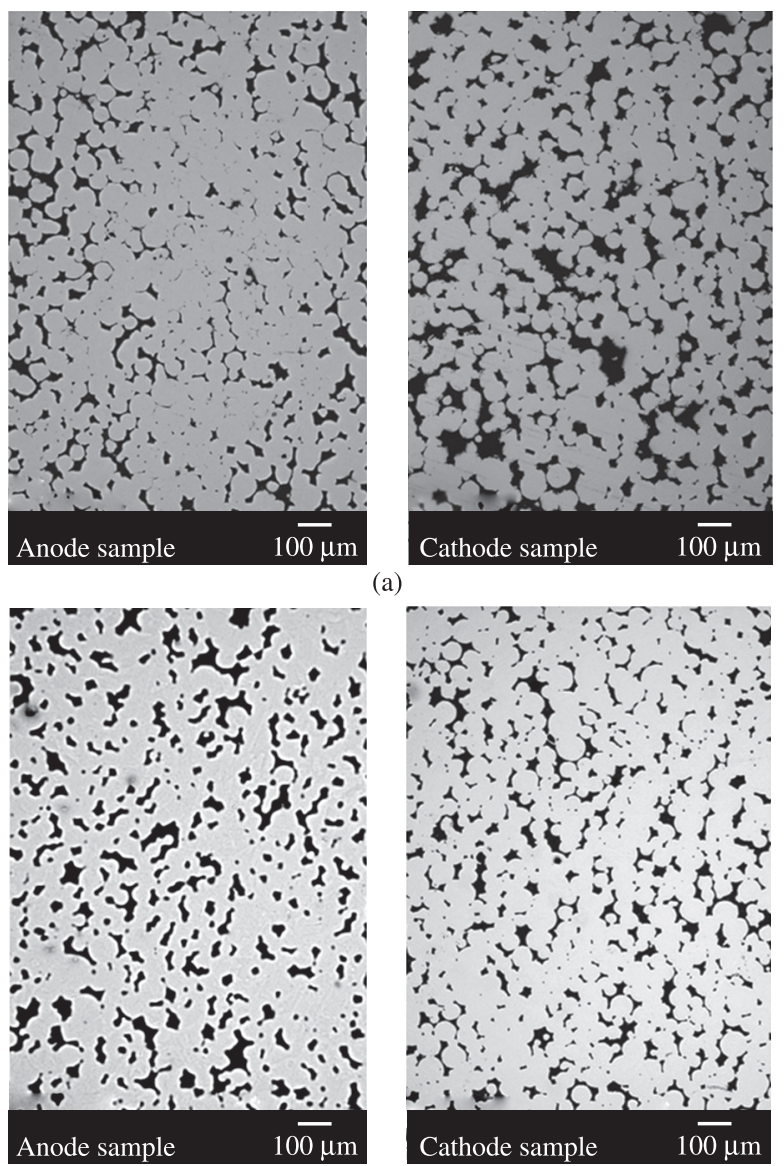

(b)

Figure 7. Micrographs of the section of the samples produced without vibration during the powder filling step, sintered at $1423 \mathrm{~K}$ for 3600 seconds and compressed at (a) $300 \mathrm{MPa}$ and (b) $600 \mathrm{MPa}$.
1473 and $1523 \mathrm{~K}$. The microstructures obtained under these conditions are shown in Figures 10 to 12. The sequence of micrographs indicates the possible presence of oxides in the samples that were sintered at temperatures of 1473 and $1523 \mathrm{~K}$, resulting in a lower

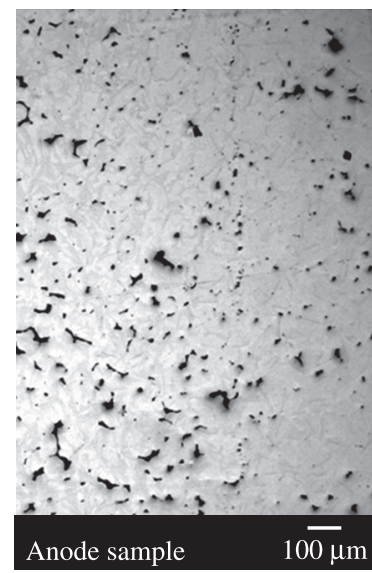

(a)

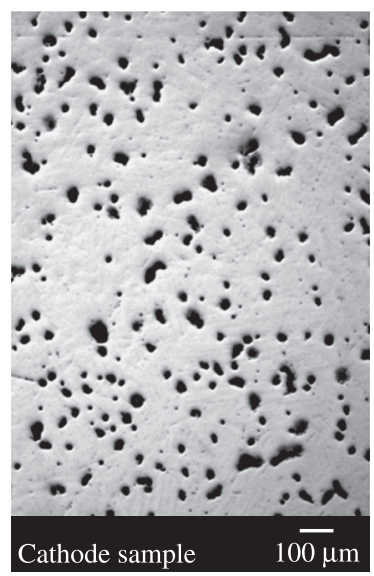

(b)
Figure 8. Micrographs of sample compacted under vibration at $600 \mathrm{MPa}$ and sintered in plasma at $1423 \mathrm{~K}$ for 3600 seconds.

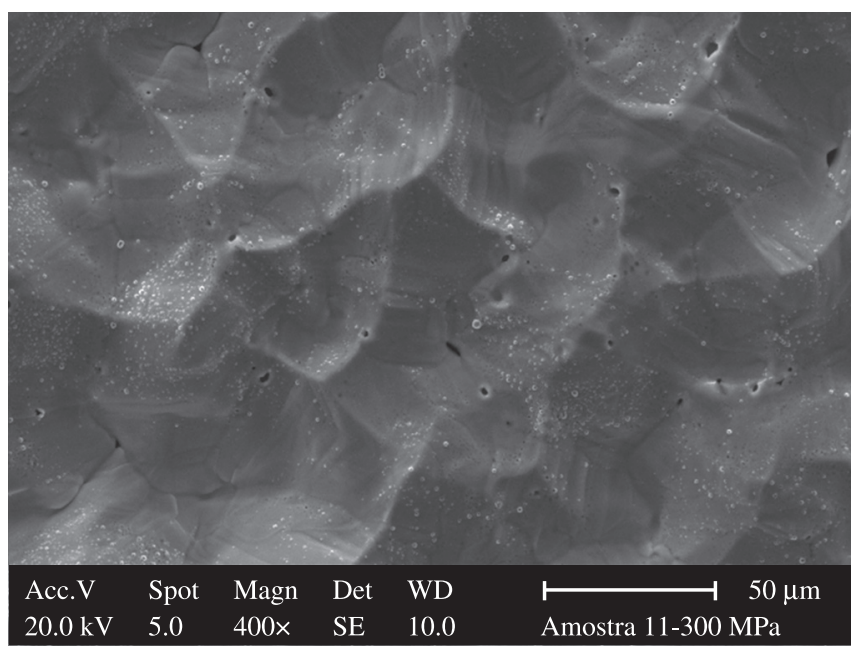

Figure 9. Electronic micrograph of the surface of a sample sintered on the cathode.

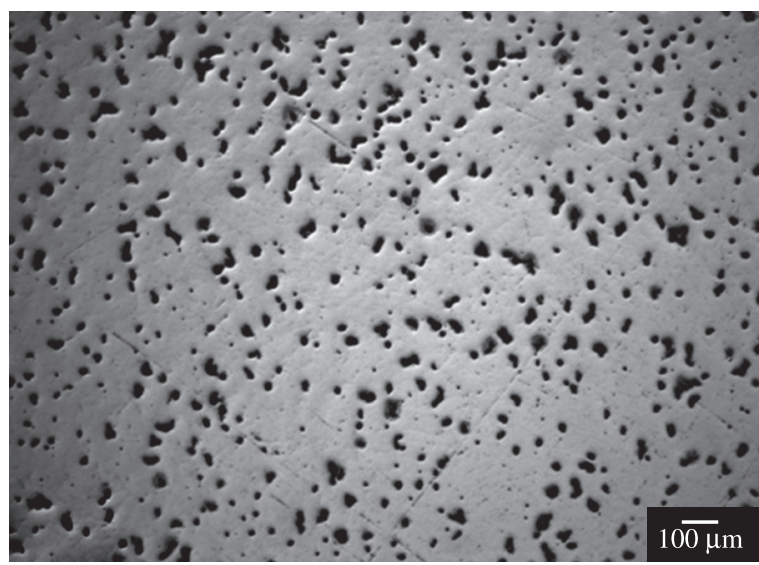

Figure 10. Microstructure of a sample pressed at $600 \mathrm{MPa}$ and sintered on the cathode at $1423 \mathrm{~K}$ for 3600 seconds. 
sintering rate, noticeable by the lower coalescing and pores rounding, if compared to the sample that was sintered at a temperature of $1423 \mathrm{~K}$. This assumption can be substantiated by analysis of the values of free energy for some types of titanium oxides, as shown in Table 4. These values indicate that in the temperature range used for sintering, the oxides of titanium have high stability. These remain in this condition until the temperature of $2446 \mathrm{~K}$.

The evolution of the pore-shape from irregular to the round geometry during the sintering step, is a clear indication of the increase of sintering contacts, thus facilitating the diffusion and resulting in a greater degree of rounding and coalescing.

Another fact to consider is the grain growth that occurs at very high sintering temperatures. The grain boundary acts as a "sink of vacancies" for the elimination of pores, which constitute "sources of vacancies." The coalescing of pores is explained by the dependence

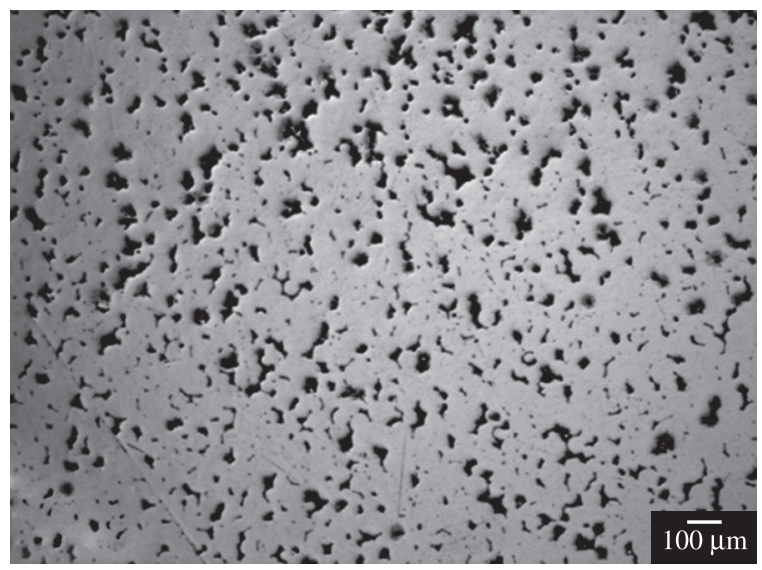

Figure 11. Microstructure of a sample pressed at $600 \mathrm{MPa}$ and sintered on the cathode at $1473 \mathrm{~K}$ for 3600 seconds.

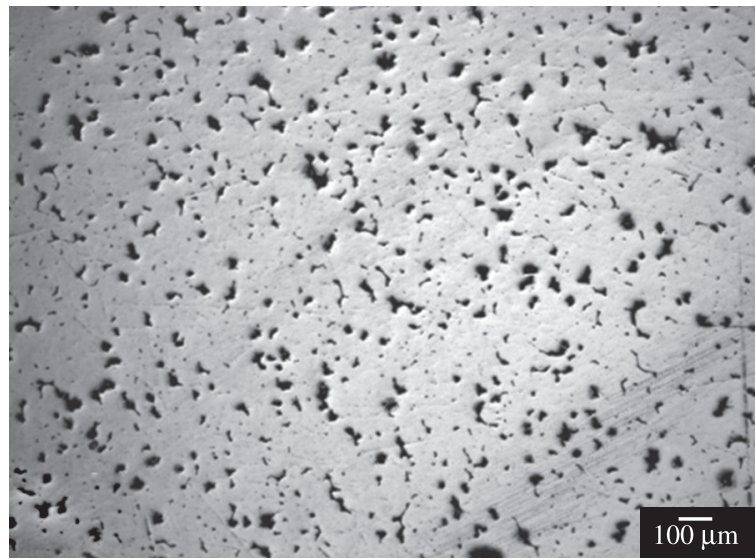

Figure 12. Microstructure of a sample pressed at $600 \mathrm{MPa}$ and sintered on the cathode at $1523 \mathrm{~K}$ for 3600 seconds. of the solubility of vacancies on the curvature radius of the pore. According to Werner Schatt apud Thümmler ${ }^{14}$, the solubility of vacancies is inversely proportional to the curvature radius of the pore. Thus, there is a greater concentration of vacancies in the crystal lattice at the vicinity of small pores, since they have smaller curvature radius, than at the vicinity of large pores that have a larger curvature radius. The gradient of vacancies generated in the solid between the small pores and large pores promotes a net flow of vacancies from the smaller pores to the larger ones, where they are absorbed, increasing the average size of the pore along the sintering time, when the number of vacancies that are absorbed by the pore becomes greater than the number of vacancies re-dissolved in the volume of the solid in the vicinity of the considered pores. It is needless to say that the elimination of pores also occurs due to the curvature radius within it. Depending on the gradient established, vacancies in the solid dissolved in the vicinity of the pore diffuse and, when they find a grain boundary or the outer surface (sink of vacancies), they are eliminated.

The possible presence of oxides in the sintered samples is attributed to the higher chemical potential of oxygen present inside the sintering chamber at higher temperatures, due to evaporation/sublimation of larger oxide pellicles and adsorbed atoms in the material that makes up the interior of the sintering chamber (in this case, the actual titanium cathode and anode used to generate the plasma) and other possible sources of oxygen. Furthermore, with a highest sintering temperature, the reactivity increases. On the other hand, oxygen has a high solubility in $\alpha$ - Ti and in $\beta$ - Ti for the sintering temperatures used, as illustrated by the $\mathrm{Ti}-\mathrm{O}$ phase diagram shown in Figure 13. This effect would ensure the solubility of oxygen in a sintering level, dissolving the oxide phase on the surface, existent in the powder particles, and ensuring the success of the titanium sintering.

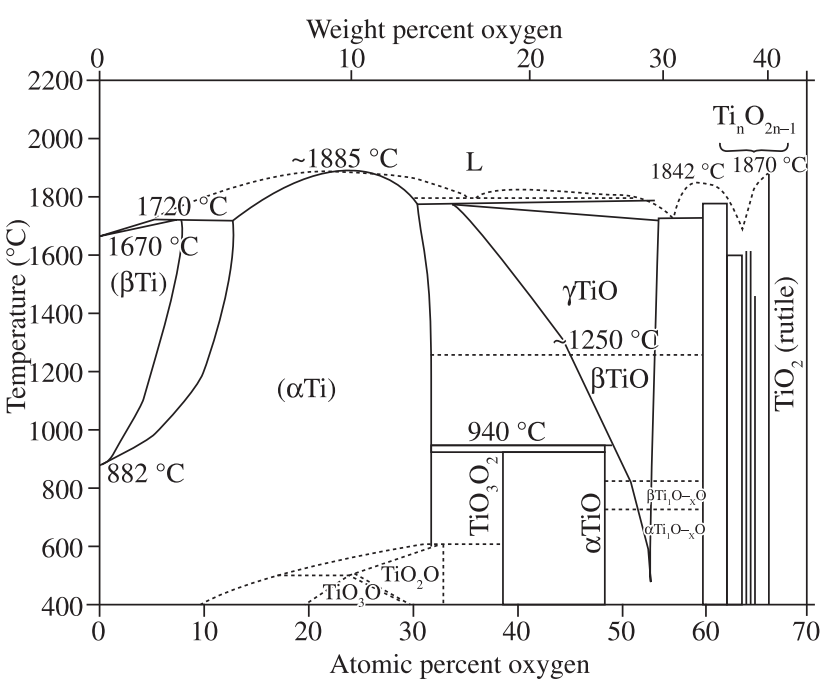

Figure 13. Phase diagram of $\mathrm{Ti}-\mathrm{O}^{18}$.

Table 4. Gibbs free energy for formation of oxides and titanium hydrides ${ }^{14}$.

\begin{tabular}{ccccccc}
\hline Temperature $(\mathrm{K})$ & \multicolumn{5}{c}{$\Delta \mathrm{G}$ values must be multiplied by 1000 J.(K.mol) } \\
\cline { 2 - 6 } & \multicolumn{1}{c}{$\mathrm{TiO}$} & $\mathrm{Ti}_{4} \mathrm{O}_{7}$ & $\mathrm{Ti}_{3} \mathrm{O}_{5}$ & $\mathrm{Ti}_{2} \mathrm{O}_{3}$ & $\mathrm{TiO}_{2}$ & $\mathrm{TiH}_{2}$ \\
\hline 300 & $-513,096$ & $-3.211,828$ & $-2.316,413$ & $-1.433,283$ & $-889,063$ & $-104,829$ \\
700 & $-474,315$ & $-2.960,15$ & $-2.137,692$ & $-1.320,568$ & $-815,93$ & $-48,985$ \\
1100 & $-437,155$ & $-2.718,921$ & $-1.969,317$ & $-1.215,497$ & $-744,912$ & 7,479 \\
1500 & $-401,244$ & $-2.479,914$ & $-1.801,84$ & $-1.112,637$ & $-673,947$ & 64,148 \\
1900 & $-367,594$ & $-2.245,751$ & $-1.638,776$ & $-1.012,831$ & $-603,732$ & 120,032 \\
\hline
\end{tabular}




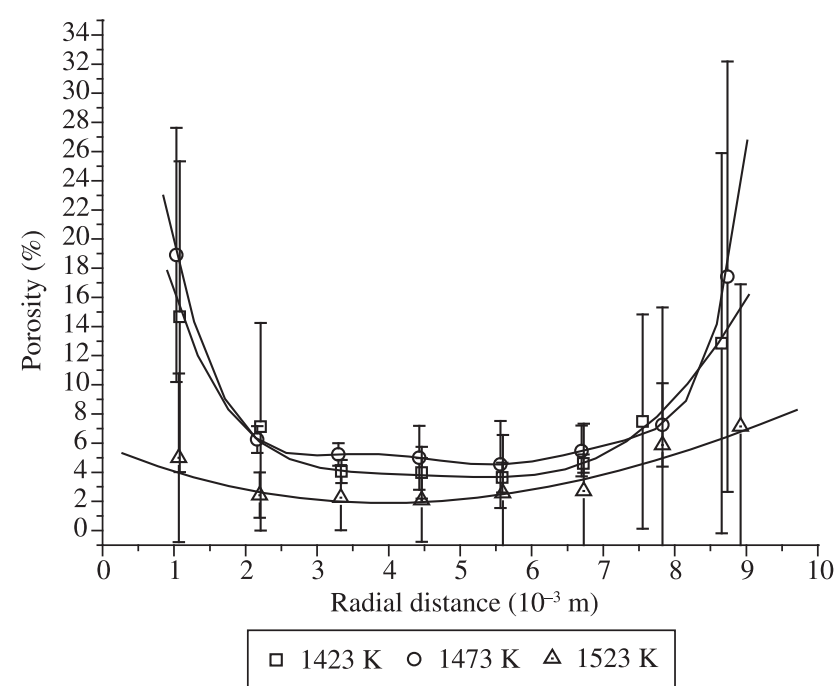

Figure 14. Behavior of porosity along the diameter of the sample for the different sintering temperatures used to sinter the samples in CAN configuration.

In this light, one can see the possible existence of two concurrent events: the formation of oxides by increasing the partial pressure of oxygen in the atmosphere of the reactor and increasing the solubility of oxygen in $\mathrm{Ti}$ at high temperatures. Therefore, as the microstructures presented show good sintering of titanium at the temperatures at which the samples were processed, it is believed that the residual oxygen in the mix is consumed in the plasma, with no increase in the formation of oxides on the surface of the particles. This effect was confirmed by Egert ${ }^{17}$ in his study on the nitriding of iron samples by plasma. In his work, Egert investigated the influence of $\mathrm{O}_{2}$ in the process with the mass spectrometry technique. Their results showed that the gas was consumed by the plasma forming $\mathrm{CO}_{2}$ and $\mathrm{OH}$.

Figure 14 shows the variation in the percentage of pores due to the diameter or radial distance to the cylindrical samples sintered in this work. The porosity is higher in the outer layers of the sample. This gradient of porosity from the outer surface to the interior of the samples is due, in part to the powder compaction process. The effective stress along the radius in the compression of a cylinder, as well as along the height, decreases because of the loss of load due to friction between the powder particles. In this case, as lubricant wasn't mixed to the powder for its compaction, the effect is more pronounced than normal. However, the gradient tends to decrease during sintering, except in cases where such phenomena as oxidation, carburization or nitriding occur, which are generally more pronounced in the outer layers, where the elements involved in the reaction reach the interior of the material through the porosity only until a certain depth. The effect decreases towards the surface to the interior for two reasons: (1) the increasing difficulty of access of oxygen to the interior through the porosity is no longer communicative with the passage of time and (2) the effect of reducing the concentration of chemical known to react with the material is consumed and becomes dependent on the renewal of the gas over the porous channels. Thus, it is expected that oxidation or other reaction will be more pronounced in the outer layers of the sample, making the densification difficult, and generating a gradient of porosity, presenting higher porosity on the outside.

\section{Conclusions}

Many of the mechanical properties of sintered components are strongly related to porosity level, as well to size and morphology of the pores. These features can be used as an indicative parameter of the evolution and control of sintering cycle suffered by the component. The process of sintering in mono-metallic materials, as it is the case of the sintering of pure titanium, occurs primarily through two mechanisms of mass transportation: Collective and individual transportation of atoms. As no external load was applied during sintering, we can neglect the collective mass transportation in the present study. And yet, considering that the vapor pressure for $\mathrm{Ti}$ at this temperature is very low, the mechanism of mass transportation via the gas phase by evaporation and condensation can also be neglected. Therefore, it is believed that the volume, surface and grain boundary diffusion are the mechanisms that control the sintering of pure titanium. The diffusion via vacancies within the material, that is, auto-diffusion of atoms in the reverse direction of movement of the vacancies, is proportional to the processing temperature, resulting in a change in pore size and morphology. Moreover, the atomic hydrogen present in the discharge may extend into the interior of the sample affecting the energy required for generation and handling the vacancies. Thus, it appears that the sintering of pure titanium assisted by plasma can be successful. It appears that this process ensures a high degree of purity of the atmosphere, reducing the contamination of the samples during sintering in comparison to conventional sintering.

\section{Acknowledgements}

Thanks to UNOESC and the graduate program in Materials Science and Engineering of UFSC for the collaboration and financial support.

\section{References}

1. Froes FH and Eylon D. Titanium Powder Metallurgy - A Review. In Titanium Net Shape Technologies: Proceedings of a Symposium. Metallurgical Society of AIME, TMS-AIME Nonferrous Metals Committee; 1984. p. 1-20.

2. Panigrahi BB and Godkhindi MM. Sintering of Titanium: Effect of Particle Size. International Journal of Powder Metallurgy. 2006; 42(2):35-42.

3. Froes FH and Eylon D. Developments in titanium powder metallurgy. Journal of Metals. 1980; 32(2):47-54.

4. Oh I, Nomura N, Masahashi N and Hanada S. Mechanical properties of porous titanium compacts prepared by powder sintering. Scripta Materialia. 2003; 49:1197-1202.

5. Oh I, Nomura N and Hanada S. Microstructures and Mechanical Properties of Porous Titanium Compacts Prepared by Powder Sintering. Materials Transactions. 2002; 43:443.

6. Wen CE, Mabuchi M, Yamada Y, Shimojima K, Chino Y and Asahina T. Processing of biocompatible porous Ti and Mg. Scripta Materialia. 2001; 45:1147-1153.

7. Pavanati HC, Maliska AM, Klein AN and Muzart JLR. Sintering unalloyed iron in abnormal glow discharge with superficial chromium enrichment. Materials Science and Engineering A. 2005; 392:313-319.

8. Muzart JLR, Batista VJ, Franco CV and Klein AN. Plasma sintering of AISI 316L stainless steel: the influence of the processing cycle on the sample density. Advances in Powder Metallurgy and Particulate Materials. 1997; 3:77-84.

9. Batista VJ, Binder R, Klein AN and Muzart JLR. Sintering iron in abnormal glow discharge. International Journal of Powder Metallurgy. 1998; 34(8):55-62.

10. Batista VJ, Mafra M, Muzart JRL, Klein AN and Back N. Plasma Sintering: A Novel Process for Sintering Metallic Components. Materials Science Forum. 1999; 299(3):249-253. 
11. Brunatto SF, Khün I, Klein AN and Muzart JLR. Sintering iron using a hollow cathode discharge. Materials Science and Engineering A. 2003; 343:163-169.

12. Maliska AM, Pavanati HC, Klein AN and Muzart JLR. The influence of ion energy bombardment on the surface porosity of plasma sintered iron. Materials Science and Engineering A. 2003; 352:273.

13. Campo FA and Escoar JA. Modeling of Superficial Sintering Enhancement by Abnormal Glow Discharge (AGD). In press.

14. Thummler F and Oberacker R. Introduction to Powder Metalurgy. London: The Institute of Materials; 1993. 332 p.
15. German RM. Powder Metallurgy Science. 2nd. ed. Princeton, New Jersey: Metal Powder Industries Federation; 1994. 472 p.

16. ASM Handbook. Powder Metalurgy. 9th edition. The Materials Information Society; 1995.

17. Egert P, Maliska AM, Silva HRT and Speller CV. Decarburization during plasma nitriding. Surface and Coatings Tech. 1999; 221:33-38.

18. MURRAY JL and WRIEDT HÁ. Ti-O phase diagram, In: BOYER R, WELSCH G and COLLINGS EW. Materials properties handbook: titanium alloys. Ohio, Estados Unidos: ASM International; 1994. p. 130. 